\title{
Leukoencephalopathy with Vanishing White Matter
}

National Cancer Institute

\section{Source}

National Cancer Institute. Leukoencephalopathy with Vanishing White Matter. NCI

Thesaurus. Code C122664.

A rare, progressive neurological disorder inherited in an autosomal recessive pattern. It is caused by mutations in the EIF2B1, EIF2B2, EIF2B3, EIF2B4, and EIF2B5 genes, resulting in deterioration of central nervous system's white matter. Usually, there are no signs and symptoms of the disorder at birth. During early childhood, affected individuals develop spasticity and ataxia which may be associated with deterioration of the metal function. Examination of the brain at autopsy reveals normal gray matter while the white matter is soft and gelatinous with numerous small cavities. 